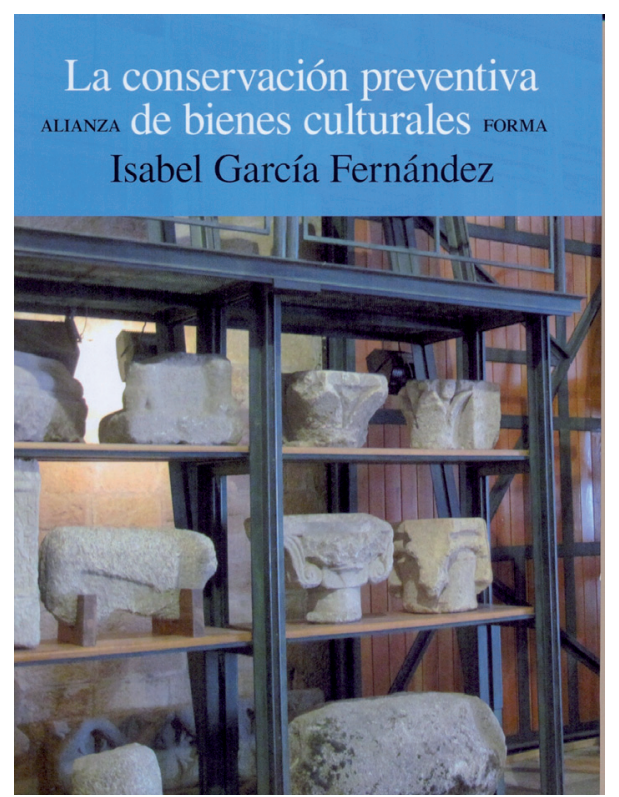

\section{La conservación preventiva de los bienes culturales}

\section{Isabel García Fernández}

\author{
Alianza Forma. Madrid, 2013 \\ 301 páginas, ilustraciones en blanco y negro, $18 \times 23 \mathrm{~cm}$.
}

ISBN: 978-84-206-7856-8
Con la garantía de la editorial Alianza Forma se presenta este nuevo texto titulado La conservación preventiva de los bienes culturales que su autora, Isabel García Fernández, de la Universidad Complutense de Madrid, propone como resultado de sus investigaciones después de más de veinte años dedicados al estudio de la denominada conservación preventiva. Tal y como ella misma apunta en la introducción del libro, éste responde a la necesidad de sistematización de estudios que sean de utilidad a las instituciones y profesionales en cuanto a la puesta en práctica de planes de conservación preventiva, de evaluación de los riesgos y del establecimiento de directrices adecuadas para el proyecto expositivo.

No sería justo decir que este reciente volumen es una nueva edición del antiguo La conservación preventiva y la exposición de objetos y obras de arte, que la misma autora publicó en 1999 fruto de sus estudios y experiencias en diferentes instituciones como ICC canadiense o el ICROM de Roma, ya que en catorce años el panorama de la conservación preventiva ha evolucionado mucho. Nuevos títulos se han sumado a los existentes, si bien estos suelen ser obras de carácter específico como las series de la editorial Trea sobre manifestaciones artísticas concretas o sobre aspectos diversos del patrimonio. Este libro supone, empero, un estudio general pero riguroso que recoge los avances, estudios y nuevos puntos de vista que se han ido desarrollando en los últimos quince años en el campo de la conservación preventiva y que, en algunas cuestiones, han supuesto un cambio de paradigma.
El libro se compone de seis capítulos, glosario de términos, bibliografía e índice analítico. El primero de ellos -"La conservación preventiva"- está dedicado precisamente a esclarecer el significado de ésta al tiempo que procura un repaso histórico exhaustivamente documentado sobre la evolución de la citada disciplina. Establece también las estrategias para la conservación de los bienes culturales, explicando cuál es el valor y el significado de las colecciones, y poniendo de manifiesto las propuestas que se han llevado a cabo en instituciones de otros países para categorizar los bienes culturales en función de ese valor-histórico, cultural, social, etc.- y de esta manera establecer jerarquías para actuar con un plan determinado en caso de riesgo para las colecciones.

Le sigue un segundo capítulo de eminente carácter práctico, "Aplicación de la conservación preventiva. La evaluación", donde se proponen los planes de conservación, la evaluación de los riesgos, el establecimiento de los estándares o directrices medioambientales, la evolución de este concepto a lo largo del tiempo y la importancia que ha supuesto para todos los profesionales dedicados a la conservación del patrimonio la concreción de los agentes de deterioro en una lista de solamente diez. En este capítulo se recogen también una relación de las evaluaciones y publicaciones más relevantes en el campo de la conservación preventiva de los últimos cuarenta años (desde 1975 a 2015), así como una cronología de los hechos más relevantes en la conservación preventiva (desde 1872 a 2012). 
Los siguientes capítulos se dedican a cuatro de los citados agentes de deterioro por ser todos ellos de tipo ambiental: la humedad relativa, la temperatura, la iluminación y las partículas contaminantes. El capítulo tercero se centra en las alteraciones y/o deterioros que pueden sufrir los objetos por su exposición a índices de humedad o de temperatura no adecuados o contraindicados y en la relación directa que se establece entre el clima exterior del museo o entidad y el interior. Por otra parte, aporta las estrategias de medición y control de la humedad y la temperatura, al tiempo que enseña a crear microclimas para la preservación de objetos en los museos, tanto por la utilización de métodos pasivos como el gel de sílice, como por los métodos activos, como pueden ser las unidades de climatización dependientes de la red eléctrica.

La compleja cuestión de la iluminación se desarrolla en el capítulo cuarto. En él que se explica qué es el espectro lumínico y se describen las distintas fuentes de luz utilizadas en las salas, almacenes o museos. Asimismo, se enumeran todos los procesos de deterioro causados por la luz en sus distintos espectros infrarrojo, ultravioleta y visible, y se proponen las estrategias para controlar y medir las radiaciones lumínicas, así como, reducir o minimizar los efectos irreversibles sobre los objetos o especímenes.

El capítulo quinto se centra en el último de los agentes ambientales, la contaminación. En él, se consignan y describen los distintos tipos de contaminantes que pueden afectar a los objetos, sus fuentes de emisión y las reacciones químicas que se producen en el seno de los objetos conservados. Seguidamente, se establecen los métodos de control de dichos contaminantes, que se llevan a cabo mediante la medición del aire y el posterior control de los agentes por medio del bloqueo o del filtrado, por mencionar sólo unos ejemplos.

Conjugando los dos grandes intereses que preocupan a la autora, se propone un último capítulo: "La conservación preventiva y el proceso expositivo". En él se recuperan y actualizan algunos de los aspectos tratados en Diseño de exposiciones. Concepto, instalación y montaje que Luis Alonso Fernández e Isabel García Fernández publicaron en esta misma editorial en 1999 y posteriormente actualizaron en 2010.

Finalmente el texto incluye un glosario de términos, y para terminar, una amplia y actualizada bibliografía de los temas tratados.

La formación internacional de la autora, su experiencia en el estudio de diversas colecciones, entre ellas las pertenecientes a la Universidad Complutense - de la que ella forma parte de su claustro docentey su dilatada carrera, han permitido producir este magnífico estudio del panorama internacional en el campo de la preservación del patrimonio.

Escrito en un lenguaje claro y directo, este libro puede ser de utilidad a conservadores, restauradores, historiadores, investigadores del patrimonio, estudiantes y en especial a todas las personas pertenecientes a instituciones, museos o entidades que custodian nuestros bienes culturales.

Montaña Galán Caballero

Universidad Complutense de Madrid 